\title{
1 NMR profiling clarifies the characterization of Finnish honeys of different botanical
}

\section{origins}

3

4 Maaria Kortesniemi ${ }^{a, b}, *$, Carolyn M. Slupsky ${ }^{b, c}$, Tarja Ollikka $^{d}$, Lassi Kauko ${ }^{e}$, Ann R. Spevacek $^{b}$, Olli

$7 \quad{ }^{a}$ Food Chemistry and Food Development, Department of Biochemistry, Fl-20014 University of

8 Turku, Finland

$9{ }^{b}$ Department of Food Science and Technology, University of California, Davis, CA 95616-5270, USA

$10{ }^{\mathrm{C}}$ Department of Nutrition, University of California, Davis, CA 95616-5270, USA

$11{ }^{d}$ The Finnish Beekeepers' Association, Fl-00130 Helsinki, Finland

$12{ }^{\mathrm{e}}$ Environmental Office of Pyhäjärvi Region, FI-27800 Säkylä, Finland

13 Environmental Health Services, City of Lohja, FI-08101 Lohja, Finland

* Corresponding author. Tel.: +358 23336813. E-mail address: mkkort@utu.fi (M. Kortesniemi).

16

17 Abstract

18 The Finnish varietal honeys are valued specialty foods with unique characteristics, owing to their

19 botanical origin. ${ }^{1}$ H NMR metabolomics was applied to examine the compositional differences and

20 origin-related markers of naturally complex boreal honeys (buckwheat, clover, dandelion, heather,

21 Himalayan balsam, honeydew, linden, lingonberry, multifloral). Special focus was on the

22 metabolites in aqueous samples. Chloroform extracts of selected samples were also analyzed for

23 additional metabolic evidence. 
24 Qualitative profiling revealed 2-hydroxy-3-methylbutyric, 2-hydroxy-3-methylpentanoic, 3-methyl-

25 2-oxopentanoic and 4-methyl-2-oxopentanoic acids as specific markers for dandelion (Taraxacum 26 spp.) honeys. Full discrimination of buckwheat, dandelion, heather, and honeydew honeys was 27 achieved with principal component analysis (PCA) and orthogonal partial least squares 28 discriminant analysis (OPLS-DA). Melezitose, glucose, and fructose explained $83 \%$ of the variation 29 in the PCA. The OPLS-DA loadings highlighted the discriminatory effect of the origin-specific non30 saccharide metabolites.

31 This study is a platform for a national honey library and analysis service. The results will facilitate 32 and rationalize the characterization and quality control of the boreal varietal honeys.

33

34 Keywords

$35 \quad{ }^{1}$ H NMR; Botanical origin; Honey; Metabolomics 
37 Honey, as defined in the Codex Standard 12-1981 (Codex Alimentarius, 2011) and the Council Directive 2001/110/EC (European Union, 2002), is a complex natural product made by honeybees

39

40

41

42

43

44

45

46

47

48

49

50

51

52

(Apis mellifera L.). The physicochemical characteristics and sensory properties of honey are determined by the origin of the honey raw material - floral nectar or honeydew, the sugary secretions of sap-sucking insects. Varietal or unifloral honeys mainly originate from one plant source, indicated by the predominant pollen type (> 45\%) (von der Ohe, Persano Oddo, Piana, Morlot, \& Martin, 2004). Determining the origin of honey is essential when assessing its quality, authenticity, bioactive potential and commercial value. In the Arctic and boreal environment, the production of pure unifloral honeys is a challenge because many plants flower coincidentally. Therefore, Finnish varietal honeys, considered as valued specialty foods, are likely to contain nectar and pollen from secondary sources, which complicates their characterization by commonly used methods. The main source of nectar and the country of origin should be indicated in the labeling as regulated by law (European Union, 2002; Codex Alimentarius, 2011).

Varietal honey types are generally identified based on sensory (Piana, Persano Oddo, Bentabol, Bruneau, Bogdanov, \& Gyuot Declerck, 2004) and melissopalynological (microscopic analysis of the pollen present in the honey) analyses (Louveaux, Maurizio, \& Vorwohl, 1978; von der Ohe et al., 2004), and by physical and chemical analyses (Persano Oddo, Piazza, Sabatini, \& Accorti, 1995). The harmonized methods of the International Honey Commission (IHC) are used in routine analysis of honey (International Honey Commission, 2009). Yet, several problems exist with accurate determination of botanical origin, one important issue being the natural variability of honeys (Persano Oddo \& Bogdanov, 2004), especially in the case of boreal honeys. 
58 In addition to the main components, fructose and glucose, other minor sugars, organic acids,

59

60

61

62

63

64

65

66

67

68

69

70

71

72

73

74

75

76

77

78

79

80

81

enzymes (invertase, diastase, and glucose oxidase), aroma compounds, and trace amounts of minerals are found in honey. The consistency and composition vary between different botanical origins, which also affect the taste and odor of the product. Highly aromatic honey type can dominate in natural blends, even at small quantities (Piana et al. 2004). Different honey types have varying physicochemical characteristics, such as crystallization and electrical conductivity (Bogdanov, Ruoff, \& Persano Oddo, 2004). The relative concentrations and the ratio of fructose and glucose are also useful parameters in relation to botanical origin (Bogdanov et al., 2004).

The raw material of honeydew honeys is the sugary secretion of insects (Hemiptera) feeding on plant sap. In melissopalynological analysis, elements like fungi and algae are used as indicators of honeydew instead of pollen. Honeydew honeys are distinguished by their higher electrical conductivity, lower concentrations of glucose and fructose, and the abundance of trisaccharides (mainly melezitose) compared with floral honeys (Persano Oddo et al., 1995; Bentabol Manzanares, Hernández García, Rodríguez Galdón, Rodríguez Rodríguez, \& Díaz Romero, 2011). The trisaccharide level is dependent on the insect species producing honeydew, the host plant, and the presence of ants (Fischer \& Shingleton, 2001).

Honey's botanical origin plays an important role in defining its bioactive value. In several in vivo (human and murine) and in vitro studies, honey has been shown to have a protective effect against microbes, viruses, parasites, inflammation, oxidation, mutagenicity, and tumor development (Bogdanov, Jurendic, Sieber, \& Gallmann, 2008). In 2013, Huttunen, Riihinen, Kauhanen, and Tikkanen-Kaukanen showed that Finnish honeys displayed antimicrobial activity against the human pathogen cocci (Streptococcus pneumoniae and S. pyogenes, Staphylococcus aureus) (Huttunen, Riihinen, Kauhanen, \& Tikkanen-Kaukanen, 2013). The most notable effect was achieved with willowherb (Epilobium angustifolium), heather (Calluna vulgaris), and buckwheat 
82 (Fagopyrum esculentum) honeys, followed by lingonberry (Vaccinium vitis-idaea) and cloudberry

83 (Rubus chamaemorus).

84 Melissopalynological analysis, despite its ambiguity and prerequisite for expertise, can reveal the 85 main pollen type, the presence of honeydew elements, and the geographical origin through pollens that are limited to a certain region (Louveaux et al., 1978; Anklam, 1998; von der Ohe et al., 2004; Salonen, Ollikka, Grönlund, Ruottinen, \& Julkunen-Tiitto, 2009). However, the pollen content does not necessarily reflect the actual nectar source of the honey, because some types of pollen can be over- (e.g. Salix spp. and Brassicaceae) or under-represented (e.g. Taraxacum spp.) in relation to nectar or from wind-pollinated or non-melliferous plants (e.g. Filipendula spp.)

91 (Louveaux et al., 1978; von der Ohe et al., 2004; Salonen et al., 2009; Salonen, 2011). Salonen and others have previously described the qualitative melissopalynological analyses of Finnish honeys (Salonen et al., 2009). Together with pollen analysis, the electrical conductivity, diastase and invertase activity, sugar composition, $\mathrm{pH}$ and acidity, and the contents of proline, water and 5hydroxymethylfurfural (HMF) are used in the quality assessment and characterization of unifloral honeys (Bogdanov et al., 2004). Proline, one of the main amino acids in honey, indicates that the honey is authentic and ripe (Bogdanov et al., 2004). In addition to established methodologies in honey analysis (Persano Oddo et al., 1995), several other approaches have been developed to characterize the botanical and geographical origins more accurately by analyzing the sugar, amino acid, phenolics, and volatile compositions (TomásBarberán, Ferreres, García-Vignera, Tomás-Lorente, 1993; Anklam, 1998; Conte, Miorini, Giomo, Bertacco, \& Zironi, 1998; Cotte, Casabianca, Chardon, Lhetier \& Grenier-Loustalot, 2003; Hermosín, Chicón, \& Dolores Cabezudo, 2003; Consonni \& Cagliani, 2008; Rebane \& Herodes, 104 2008; Salonen, 2011; Consonni, Cagliani, \& Cogliati, 2013). For example, different chromatographic 105 (Rebane \& Herodes, 2008) and mass spectrometric methods (Tomás-Barberán et al., 1993; 
Ampuero, Bogdanov, \& Bosset, 2004; Zhou, Yao, Li, Chen, Wu, \& Zhao, 2014), SDS-PAGE immunoblotting (Baroni, Chiabrando, Costa, \& Wunderlin, 2002), Fourier transform near-infrared (FT-NIR) spectroscopy (Ruoff et al., 2006), and DNA barcoding (Bruni et al., 2015) have been used. In recent years, honey analysis has evolved towards applying different nuclear magnetic resonance (NMR) spectroscopic approaches. Having showed diverse applicability and accuracy in quantitative/targeted analysis of metabolites (Sandusky \& Raftery, 2005; Ohmenhaeuser, Monakhova, Kuballa, \& Lachenmeier, 2013; Spiteri et al., 2015), authentication (Bertelli, Lolli, Papotti, Bortolotti, Serra, \& Plessi, 2010; Boffo, Tavares, Tobias, Ferreira, \& Ferreira, 2012; Spiteri et al., 2015), and in determining geographical (Consonni \& Cagliani, 2008; Consonni et al., 2013; Donarski, Jones, \& Charlton, 2008) and botanical origin (Ohmenhaeuser et al., 2013; Zieliński, Deja, Jasicka-Misiak, \& Kafarski, 2014; Spiteri et al., 2015), NMR metabolomic analysis of honey has already led to commercial use of the methods (Bruker Corporation, 2015; Spiteri et al., 2015). Yet, the applications have not extended to Nordic honey types until now. NMR metabolomics has been used in characterizing some of the Central and Southern European honey types, most commonly the acacia (more accurately, false acacia or black locust; Pseudoacacia robinia), buckwheat (Fagopyrum esculentum), chestnut (Castanea sativa), citrus or orange blossom (Citrus spp.), eucalyptus (Eucalyptus spp.), heather (Calluna vulgaris / Erica spp.), linden (Tilia spp.), and honeydew honeys (Donarski et al., 2008; Lolli, Bertelli, Plessi, Sabatini, \& Restani, 2008; Donarski, Jones, Harrison, Driffield, \& Charlton, 2010; Schievano, Peggion, \& Mammi, 2010; Schievano, Stocchero, Morelato, Facchin, \& Mammi, 2012; Schievano, Morelato, Facchin, \& Mammi, 2013; Zieliński et al., 2014). NMR enables a rapid detection of fraudulent honeys, by indicating the additions of sugar syrups diluting the honey (Bertelli et al., 2010; Spiteri et al., 2015). The presence of ethanol from microbial fermentation and 5-hydroxymethylfurfural (HMF) from excess heating and/or prolonged storage is also easily observed in the spectra (Spiteri et al., 2015). Both organic 
and aqueous extracts of honey have been used in NMR studies. Chloroform extracts of nonvolatile

131 organic components that are useful fingerprint compounds (Schievano et al., 2010), but aqueous 132 samples are also adequate in discriminating honey types based on the botanical origin (Consonni 133 \& Cagliani, 2008; Zieliński et al., 2014).

134 Here, ${ }^{1} \mathrm{H}$ NMR metabolomics was applied to analyzing boreal varietal honeys for the first time. Our 135 aim was to determine the botanical origin and the key markers of a set of Finnish honeys. The 136 described methodology will serve as platform for more unequivocal characterization and 137 authentication of the botanical origins of the honeys, benefiting the consumers, beekeeping 138 industry, and honey trade through accurate labeling and pricing of the products.

\section{Materials and Methods}

\subsection{Honey samples}

141 The botanical origins of the Finnish honey samples in focus were buckwheat (Fagopyrum 142 esculentum; $n=3$ ), dandelion (Taraxacum officinale; $n=4)$, and heather (Calluna vulgaris; $n=4$ ). 143 Samples of Himalayan balsam (Impatiens glandulifera; $n=1$ ), linden (Tilia spp.; $n=1$ ), lingonberry 144 (Vaccinium vitis-idaea; $n=1$ ), and clover (Trifolium repense/hybridum; $n=1$ ), together with three samples of honeydew honeys and two multifloral honeys were included in the study (Table 1). The samples were from eleven different beekeeper from the harvests of 2012 and 2013 . The honeys were harvested prior the end of flowering of the main plant. Dandelion and lingonberry honeys were extracted (harvested) at the end of June. All the other honey types, excluding heather, were extracted during late July-early August. Heather honey was extracted in mid-August. The honeys were handled and stored according to each beekeeper's customary practices, yet using as gentle conditions as possible. Samples 1-17 originated directly from the producers (of which 3-16 via the 
analyses were performed on approximately 400 pollen particles and the percentages of pollen

154 types were calculated (supplementary Table S1). The honey samples were stored in the dark at 155 room temperature prior to sample preparation.

156

\subsection{Chemicals}

Internal standard 2,2,3,3,4,4- $d_{6}-3$-(trimethylsilyl)-1-propane sulfonic acid (DSS- $d_{6}$ ) and sodium azide $\left(\mathrm{NaN}_{3}\right)$ in $\mathrm{D}_{2} \mathrm{O}$ was from Chenomx Inc. (Edmonton, Alberta, Canada). Sodium hydroxide and hydrochloric acid solutions were from Fisher Scientific (Fair Lawn, NJ). Chloroform $\left(\mathrm{CHCl}_{3}\right)$ and chloroform-d ( $\mathrm{CDCl}_{3}, 99.8 \%$ atom D) were purchased from Sigma-Aldrich (St. Louis, MO).

\subsection{Preparation of NMR samples}

After thorough mixing, $100 \mathrm{mg}$ of honey was dissolved in $800 \mu \mathrm{L}$ of Type I ultrapure $\mathrm{H}_{2} \mathrm{O}$ from Millipore Synergy UV system (Millipore, Billerica, MI). The samples were centrifuged for 1 min with $14,000 \times g$ at $20^{\circ} \mathrm{C}$ and the supernatant was filtered through a $3 \mathrm{kDa}$ molecular weight cut-off Amicon ultracentrifugal filter unit (Millipore). An aliquot of $207 \mu \mathrm{l}$ of the filtrate was combined with $23 \mu \mathrm{l}$ of internal standard DSS- $d_{6}$ (at $4.6187 \mathrm{mM}$ in $\mathrm{D}_{2} \mathrm{O}$, with $0.2 \% \mathrm{NaN}_{3}$ ). The $\mathrm{pH}$ of the sample containing DSS- $d_{6}$ standard was adjusted to $6.55 \pm 0.05$ with small additions of $\mathrm{NaOH}$ and $\mathrm{HCl} .180 \mu \mathrm{l}$ of the sample was analyzed in 3-mm NMR-tubes (Bruker Biospin Corporation, Billerica, MA). Three technical replicates per sample were performed to minimize possible matrix inhomogeneity.

In addition to the aqueous samples, few samples were prepared according to the chloroformwater extraction method by Schievano and others (Schievano et al., 2010). The chloroform layer was concentrated until dry with MiVac Duo concentrator (Genevac Inc., Stone Ridge, NY). The residue was re-dissolved in $600 \mu \mathrm{l} \mathrm{CDCl} 3$ and transferred to a 5-mm NMR tube. 
The ${ }^{1} \mathrm{H}$ NMR spectra of the aqueous samples were acquired at $298 \mathrm{~K}$ on a Bruker $600 \mathrm{MHz} \mathrm{NMR}$ spectrometer (Bruker BioSpin AG, Fällanden, Switzerland) equipped with a $\mathrm{TCl}$ cryoprobe and a SampleJet using the noesypr1d pulse programs. A number of 128 scans were collected over $32 \mathrm{k}$ data points, with 16 dummy scans, sweep width of $12 \mathrm{ppm}$, acquisition time of $2.5 \mathrm{~s}$, relaxation delay of $2.5 \mathrm{~s}$, and mixing time $100 \mathrm{~ms}$. The receiver gain was set to 32 . Water presaturation during relaxation delay and mixing time was achieved with a $70 \mathrm{~dB}$ irradiation. The spectra were zero-filled to $128 \mathrm{k}$ data points. Chenomx NMR Suite 8.0 (Chenomx Inc., Edmonton, Canada) was applied to manually correct the phase and baseline. Shim correction to $0.5 \mathrm{~Hz}$ and line broadening of $0.5 \mathrm{~Hz}$ were applied. Prior multivariate data analyses, the spectra were normalized to total spectral area and binned using $0.02 \mathrm{ppm}$ bin width. The water peak at 4.88-4.92 ppm was excluded.

187 The acquisition parameters for the qualitative ${ }^{1} \mathrm{H}$ NMR experiment (zg30) of the organic extracts in $188 \mathrm{CDCl}_{3}$ at $298 \mathrm{~K}$ were: number of scans, 512; number of dummy scans, 8; data points, $32 \mathrm{k}$; spectral width, $14 \mathrm{ppm}$. The chemical shifts $(\delta)$ were referenced to the $\mathrm{CHCl}_{3}$ residual peak at $7.26 \mathrm{ppm}$.

\subsection{Data analysis}

191 The chemical shifts were assigned with literature, databases (HMDB, YMDB), the Chenomx 192 Profiler, and an in-house library of saccharide standard compounds. In the multivariate data 193 analyses, The SIMCA-P+ v12.0.0.0 software (Umetrics AB, Umeå, Sweden) was used. The primary 194 dataset of 62 observations and 458 X-variables (bins) were Pareto-scaled prior principal 195 component analysis (PCA) and orthogonal partial least squares-discriminant analysis (OPLS-DA) 196 (Eriksson, Byrne, Johansson, Trygg, \& Wikström, 2013). 


\subsection{Melissopalynological analysis}

The melissopalynological analyses (supplementary Table S1) highlighted the ambiguity in the characterization of Finnish honeys (Table 1). The most common pollen types in the samples were Brassicaceae, Apiaceae, Rubus spp., Trifolium spp., and Salix spp. However, many of these pollen types were over-represented, while the pollen from a plant source giving the honey its main characteristic may be present in very minor proportions, which was the case with buckwheat (Fagopyrum esculentum), heather (Calluna vulgaris), dandelion (Taraxacum spp.), and linden (Tilia spp.) (von der Ohe et al., 2004; Salonen, 2011). Dandelion honeys usually feature a high proportion of pollen from Salix spp., which was also seen in the present samples (Persano Oddo et al., 1995; Salonen, 2011). Although being a non-melliferous plant, Filipendula spp. are a common source of pollen in Finnish honey (Salonen et al., 2009). Pollen from the Brassicaceae family (most likely from the turnip rape, Brassica rapa) was the most abundant group in the samples. Often the nectar source defining the characteristic properties was present only at minor levels. Dandelions produce little or no pollen, which may explain the fact that some of the dandelion honeys contained Taraxacum pollen only at levels below $3 \%$.

\subsection{Qualitative analysis of aqueous NMR samples}

The NMR metabolomic profiles are presented in Fig. 1. Highlighted fingerprints of selected samples in different spectral regions are shown in Fig. 2. The fingerprints were consistent within the sample groups but their levels differed. The aqueous extracts of buckwheat honeys had higher levels of amino acids isoleucine, leucine, threonine, tyrosine, valine, and 4-hydroxybenzoic acid (d 7.80 and d 6.91 ppm) (Fig. 2A-B and Fig. 2E). Also, the unassigned resonances at 5.04 (broad s), 
6.67 (d), $6.70(\mathrm{dd})$, and $6.80 \mathrm{ppm}(\mathrm{s})$ could serve as potential indication of the origin in buckwheat honeys. Tyrosine and 4-hydroxybenzoic acid have been reported as buckwheat markers earlier (Steeg \& Montag, 1987; Zieliński et al., 2014). Phenylalanine and tyrosine have also been reported to be markers for lavender (Lavandula) honey (Hermosín et al., 2003). The levels of isoleucine, 223 leucine, and valine ( $\delta 1.1-0.9 \mathrm{ppm}$ ) were relatively high in buckwheat honeys (Fig. 2A).

224 2-hydroxy-3-methylbutyric acid (2-hydroxyisovaleric acid; $\delta \quad 0.82,0.96 \mathrm{ppm}$ ), 2-hydroxy-3225 methylpentanoic acid (2-hydroxy-3-methylvaleric acid; $\delta 0.86,0.93$ ppm), 3-methyl-2oxopentanoic acid (3-methyl-2-oxovaleric acid; $\delta 0.88,1.09 \mathrm{ppm}$ ), and 4-methyl-2-oxopentanoic acid (2-oxoisocaproic acid; $\delta 0.93,2.60 \mathrm{ppm}$ ) were assigned with the Chenomx Profiler specifically to dandelion honeys (Fig. 2A-B). Their chemical structures with proton assignments are shown in Fig. 3. The doublets at $\delta 0.78$ and $1.11 \mathrm{ppm}$ were also characteristic to these honeys. These compounds may be products of microbial fermentation, but still specific for this origin, as was the 231 high glucose content (Salonen, 2011).

232 In addition to melezitose and trehalose, distinctive honeydew markers were found from the 233 aliphatic and aromatic regions. The honeydew honeys were characterized by fumaric, lactic, malic, 234 and succinic acids, and the presence of asparagine and aspartic acid at detectable levels (Fig. 2A-B 235 and Fig. 2E). Other markers were observed at $\delta 5.58$ and $6.43 \mathrm{ppm}$ (Fig. 2E). Clover honey lacked 236 any apparent signature markers, but was distinguished by its low levels of glucose. The known 237 linden marker, 1-O-B-gentiobiosyl (6-O-(6-D-glucopyranosyl)-6-D-glucopyranosyl) ester of 4-(1238 hydroxy-1-methylethyl)cyclohexa-1,3-diene-1-carboxylic acid was present (Naef, Jaquier, Velluz, \& 239 Bachofen, 2004; Schievano et al., 2013). Gentiobiose was the most abundantly present in the 240 linden honey. Additional unidentified fingerprints for linden honey are shown in green in Fig. 2B241 C. 
242 Heather honeys contain aromatic carboxylic acids, namely benzoic, 3-phenyllactic and 243 phenylacetic acids, which contribute to the aroma profile and their honey-like odor (Steeg \& 244 Montag, 1987). The levels of formic acid were also highest in heather honeys. A doublet at $\delta 1.92$ 245 ppm, partially overlapping with the acetic acid singlet, was found specific to heather (Fig. 2B). 3246 phenyllactic acid (PLA) may be a contributor to the high antimicrobial activity reported in heather 247 honeys (Mu, Yu, Zhu, Zhang, \& Jiang, 2012; Huttunen et al., 2013).

248 As with the dandelion-specific markers, the PLA could be a microbial metabolite of the lactic acid 249 bacteria naturally present in the honey (Mu et al., 2012). The thixotropic nature of heather honey 250 makes it prone to exhibit broad NMR peaks, especially those belonging to acids. In the aliphatic 251 region, two peaks at $\delta 1.03$ and $1.06 \mathrm{ppm}$ were characteristic to the heather honeys (Fig. 2A).

252 Any distinctive water-soluble markers were not identified for multifloral, Himalayan balsam or 253 lingonberry honey. However, the aromatic region of the lingonberry spectra contained 254 unidentified signals at low levels (Fig. 2E). Their chemical shifts in the high frequency region 255 suggest (hetero)aromatic nature.

256 Several di- and trisaccharides were assigned for each honey type, most abundant ones being 257 kojibiose, nigerose, turanose, and isomaltotriose, kestose, melezitose, raffinose, respectively (Fig. 258 2C-D). Due to the matrix effect, signal overlapping, abundancy of isomers and the co-suppression 259 of signals near the water peak, the accurate quantitative profiling of several saccharides was not 260 possible. Trigonelline and uridine were common metabolites in all the honeys, at low 261 concentrations. Ethanol and acetic acid were found in some of the studied honeys, indicating 262 fermentation. Both heather and dandelion honeys are known to be prone for excess moisture, 263 enabling the microbial fermentation. Heather honey has a relatively high moisture content of $18 \%$ 264 (Salonen, 2011), while dandelion honey may also contain excess moisture if centrifuged too early. 265 In addition to the fermentation products, the ${ }^{1} \mathrm{H}$ NMR analysis allowed the detection of 5- 
267 quality defect due to heating and prolonged storage, were generally minute in every honey (Fig. 268 2E). Therefore, the doublets at $\delta 7.53$ and $6.67 \mathrm{ppm}$ were not detected in many cases.

269 The advantage of analyzing water extracts is above all cost-efficiency: the sample handling and the 270 NMR experiment require fairly little time per sample. Also, the amount of costly deuterated 271 solvents can be reduced to $10 \%$ of the total volume without loss of spectral quality. For routine 272 and high-throughput analyses of determining honey origin the water extraction is recommended, 273 even though Schievano and others recommend chloroform for its NMR-applicable properties 274 (Schievano et al., 2010). The use of a chemical shift standard is not a necessity because the 275 chemical shifts can be adjusted e.g. to the $\alpha$-anomer of glucose at $\delta 5.23 \mathrm{ppm}$. For qualitative 276 screening of honeys, ${ }^{1} \mathrm{H}$ NMR of samples diluted with $\mathrm{D}_{2} \mathrm{O}$ is simple and fairly rapid, provided that 277 characteristics of different honey varieties are known. However, quantitative analysis of aqueous 278 extracts and extraction of organic compounds require more intricate sample preparation 279 techniques to overcome the aforementioned challenges. Viscosity of the NMR samples is an issue 280 especially with thixotropic heather honeys. The reduction of sample viscosity by dilution of 1:6 281 (w/w) was not adequate for heather honeys (Sandusky \& Raftery, 2005). The linewidth at peak 282 half-height for heather honeys was up to $4 \mathrm{~Hz}$, which is highly undesirable in quantitative analysis 283 when narrow lineshapes (peak half-width of the chemical shift indicator $\leq 1.5 \mathrm{~Hz}$ ) are required. By 284 increasing the dilution factor, the heather honeys reached the linewidths below $1 \mathrm{~Hz}$. Yet, the 285 peak belonging to acids were broad.

\subsection{Qualitative analysis of the organic extracts}

287 Qualitative analysis of $\mathrm{CDCl}_{3}$ extracts for nonpolar compounds was also performed. Honeydew honey marker diacylglyceryl ether supported the identification of this honey type (Schievano et al., 

cyclohexen-1-one), a flavor-related (but odorless) carbonyl compound, was present in heather 291 honey as expected (Häusler \& Montag, 1989). The Calluna honeys can contain dehydrovomifioliol 292 190-260 mg/kg (Häusler \& Montag, 1989). It has also been reported to be a component in 293 eucalyptus and chestnut honeys, up to levels of $6 \mathrm{mg} / \mathrm{kg}$ (Häusler \& Montag, 1989; Schievano et 294 al., 2012).

295 The chloroform extract of linden honey contained the respective aglycon of the marker found in 296 the aqueous sample, the 4-(1-hydroxy-1-methylethyl)cyclohexa-1,3-diene-1-carboxylic acid 297 (Frérot, Velluz, Decorzant, \& Naef, 2006; Schievano et al., 2012; Zieliński et al., 2014). Lingonberry 298 honey was characterized by relatively high methyl syringate (singlets at $\delta 7.33,3.95$ and $3.90 \mathrm{ppm}$ ) content. Methyl syringate was also detected at varying but low levels in all the tested honeys except honeydew. Another (unidentified) marker present in lingonberry honey had signals at $\delta$ 8.60 (singlet) and 8.52 (triplet) ppm. The singlet at $\delta 8.78 \mathrm{ppm}$ and the two doublets at $\delta 8.41$ and

$8.18 \mathrm{ppm}$ were detected only in the buckwheat honey. The Himalayan balsam honey did not have any characteristic signals in the chloroform extract to suggest botanical origin. Himalayan balsam (Impatiens glandulifera) is considered as a pernicious alien plant widely spread outside gardens and recommended to be eradicated, yet its late flowering and abundant production of high-sugar nectar benefits honey bees. Thus far, little is known about this honey type. Due the lack of biomarkers and distinctive aroma or color, the differentiation of Impatiens honey from multifloral or other mild honeys can be challenging.

\subsection{Multivariate data analysis}

310 The general sugar composition in relation to other honey types played an important part in the 311 discrimination. Principal component analysis (PCA) of the primary dataset (Fig. 4A) showed how 
312 the first principal component $\left(R^{2} X=0.50\right)$ clearly separated honeydew honeys from the floral 313 honeys. This separation was due to melezitose, the most obvious honeydew marker, as seen in the 314 loadings plot in Fig. 4B (bins 3.85, 3.63, 4.29). Trehalose had also an influence on the first principal 315 component through bins 3.63 and 3.85. The second component $\left(R^{2} X=0.33\right)$, on the other hand, 316 signified the distribution of floral honeys and was mainly explained by the most abundant sugars, 317 fructose (bins $3.79,3.57,3.55)$ and glucose $(3.73,3.45)$. Therefore, the second component may 318 serve as an indicator of the fructose/glucose ratio and a valuable indicator of probable nectar 319 source. The subsequent principal components did not resolve the issue of overlapping among the 320 floral honeys. Since the NMR spectral data did not reveal any significant markers for Himalayan 321 balsam honey, the positioning of this honey type in the center of the PCA model (Fig. 4A) could 322 serve as an indicator of the potential botanical source through the sugar composition. In addition, 323 lingonberry honey should have a relatively high fructose/glucose ratio, mainly due to its low 324 glucose content, making it also liquid (Salonen, 2011). Here, however, the presence of Rubus spp. 325 (Table S1) may have counterbalanced the sugar ratio. Yet, the low-intensity signals in both the 326 aqueous and chloroform extracts are likely to originate from the high proportion of Vaccinium spp. 327 However, since we only had one sample of clover, lingonberry and Himalayan balsam honeys, with 328 limited previous information available, any advanced conclusions on their metabolic 329 characteristics without further examination cannot be drawn.

330 Accentuated discrimination of a certain sample or a class can be achieved by using supervised 331 multivariate methods, and special approaches, like one-versus-all and pairwise comparisons, 332 where the differences between the samples in question are purposefully enhanced (Schievano et 333 al., 2010; Consonni, Cagliani, \& Cogliati, 2012; Zieliński et al., 2014). Therefore, to emphasize the 334 class discrimination, orthogonal partial least-squares discriminant analysis (OPLS-DA) was applied. 335 OPLS enhances relevant variation in $X$ that correlates with the $Y$ variable. The three largest sample 
classes of floral honeys, the buckwheat, dandelion and heather, were chosen for this examination

337 to improve their model visualization and interpretation (Fig. 5). Also, by using this supervised 338 method, identification of putative biomarkers was facilitated. The samples originated from 339 different locations and all classes included one commercial sample (Table 1).

340 The OPLS-DA models in Fig. 5 demonstrate high explained variation $\left(R^{2}>0.9\right)$ and predictive ability $341\left(Q^{2}>0.9\right)$. In the score overview of the first $\left(R^{2} X[1]=0.46\right)$ and second $\left(R^{2} X[2]=0.06\right)$ components 342 in Fig. 5A, the three classes are clearly separated. To highlight the class separation and learn the 343 discriminatory variables, pairwise OPLS-DA models were also created (Fig. 5B-D). The between344 class variations were explained by the respective loadings in Fig. 5E-G. The OPLS-DA models were 345 validated by subjecting the corresponding PLS-DA models to permutation analysis (Fig. 6). 346 Although the low observation-to-variable ratio and the use of (O)PLS-DA models are prone to 347 overfitting, the permutation tests exhibit valid models in all cases except in Fig. 6D, where the $R^{2} Y$ 348 intercept of 0.48 slightly exceeds the $0.3-0.4$ threshold (Eriksson et al., 2013).

349 The most significant loadings to discriminate the honeys corresponded to glucose (e.g. bins 5.23, $3504.63,3.83,3.73,3.43,3.23$ ) and fructose (e.g. bins $4.11,3.89,3.79,3.69,3.55)$. The low-magnitude 351 loadings, specific to buckwheat honeys, represented tyrosine $(7.19,6.89)$, unknown singlet $(5.05)$, 352 and leucine, isoleucine and valine (1.03-0.95). Tyrosine was suggested as a marker for buckwheat 353 honey (36), as was formic acid, which indeed was separating the buckwheat from the dandelion 354 honeys (Fig. 5E), but not from the heather honeys (Fig. 5G). Low levels of formic acid (8.45) were 355 characteristic to dandelion honeys, while the strongest contribution of this compound was 356 observed for heather honeys. A bin at 1.91, which is mainly acetic acid, also holds an additional 357 peak in heather honey that may be related to an acetylated metabolite. Other heather-related 358 markers were benzoic acid (7.87), phenyllactic acid (7.37, 7.31, 3.09, 2.87), dehydrovomifoliol $359(6.43,6.07)$, pyruvic acid (2.37) and proline (2.35). The OPLS-DA loadings of the models in Fig. 5 
confirmed what was visually observed in the spectral data that the low-intensity non-saccharide compounds are discriminatory.

\section{Conclusions}

363 The results of this study demonstrated the applicability of NMR-based metabolomics in 364 characterizing naturally complex Finnish honeys. Authentication and correct labeling is of utmost 365 importance to both the honey producers and the customers seeking for quality and value. 366 Producers gain advantage by higher pricing and smoother trade. The potential bioactivities and 367 the specific taste and aroma of varietal honeys are sought-after attributes. Therefore, appropriate 368 screening methods and gained knowledge of the Finnish honey types are crucial. The boreal 369 climate, short summer season, and subsequently narrow window of flowering amongst plants 370 complicate the harvest of pure varietal honeys in Finland. Hence, the varietal honeys are likely to 371 contain nectar and pollen from several botanical origins, and thus cause ambiguity in product 372 classification when using sensory, physicochemical, or melissopalynological analysis. A categorical 373 classification according to the level of varietal purity is therefore proposed.

374 Here, ${ }^{1} \mathrm{H}$ NMR metabolomics allowed a clear discrimination of Finnish buckwheat, dandelion, 375 heather, and honeydew honeys. Compositional features that would allow NMR-based 376 classification were also characterized for clover, linden, and lingonberry honeys. Qualitative 377 profiling revealed specific fingerprints were for clover, dandelion, and heather honeys. The effect 378 of the natural variation in honey composition was minimized by using the OPLS-DA, which allowed 379 the clear separation of the three honey classes: buckwheat, dandelion, and heather. Yet, more 380 work is needed to profile some of the rarest and most valued Finnish honey types, such as 381 cloudberry (Rubus chamaemorus), bilberry (Vaccinium myrtillus), and willowherb (Epilobium angustifolium) honey, while aiming towards a comprehensive national honey library. 
384 This project was made possible by support from the Magnus Ehrnrooth Foundation, the Finnish 385 Cultural Foundation, the University of Turku Graduate School's Doctoral Programme in Molecular 386 Life Sciences (UTUGS/DPMLS), the USDA National Institute of Food and Agriculture Hatch Project 387 1005945, and the National Institutes of Health (U24 DK097154). The authors wish to thank Heikki 388 Vartiainen and the Finnish Beekeepers' Association for providing the honey samples and Darya O. 389 Mishchuk for technical assistance. The UC Davis NMR facility is supported by the National 390 Institutes of Health grant RR11973.

\section{References}

393

Ampuero, S., Bogdanov, S., \& Bosset, J.-O. (2004). Classification of unifloral honeys with an MSbased electronic nose using different sampling modes: SHS, SPME and INDEX. European Food Research Technology, 218, 198-207.

Anklam, E. (1998). A review of the analytical methods to determine the geographical and botanical origin of honey. Food Chemistry, 63, 549-562.

Baroni, M. V., Chiabrando, G. A., Costa, C., \& Wunderlin, D. A. (2002). Assessment of the floral 399 origin of honey by SDS-page immunoblot techniques. Journal of Agricultural and Food Chemistry, 400 $50,1362-1367$.

401 Bentabol Manzanares, A., Hernández García, Z., Rodríguez Galdón, B., Rodríguez Rodríguez, E., \& 402 Díaz Romero, C. (2011). Differentiation of blossom and honeydew honeys using multivariate 
403 analysis on the physicochemical parameters and sugar composition. Food Chemistry, 126, 664404672.

405 Bertelli, D., Lolli, M., Papotti, G., Bortolotti, L., Serra, G., \& Plessi, M. (2010) Detection of honey 406 adulteration by sugar syrups using one-dimensional and two-dimensional high-resolution nuclear 407 magnetic resonance. Journal of Agricultural and Food Chemistry, 58, 8495-8501.

408 Boffo, E. F., Tavares, L. A., Tobias, A. C. T., Ferreira, M. M. C., \& Ferreira, A. G. (2012). Identification 409 of components of Brazilian honey by ${ }^{1} \mathrm{H}$ NMR and classification of its botanical origin by 410 chemometric methods. LWT - Food Science and Technology, 49, 55-63.

411 Bogdanov, S., Ruoff, K., \& Persano Oddo, L. (2004). Physico-chemical methods for the 412 characterisation of unifloral honeys: a review. Apidologie, 35: S4-S17.

413 Bogdanov, S., Jurendic, T., Sieber, R., \& Gallmann, P. (2008). Honey for nutrition and health: a 414 review. Journal of the American College of Nutrition, 27, 677-689.

415 Bruker Corporation (2015). FoodScreener Honey Profiling - Analytical Services for Honey Profiling. 416 https://www.bruker.com/products/mr/nmr/food-screener/honey-profiling/overview.html

417 (accessed Sep 15, 2015).

418 Bruni, I., Galimberti, A., Caridi, L., Scaccabarozzi, D., De Mattia, F., Casiraghi, M., \& Labra, M. 419 (2015). A DNA barcoding approach to identify plant species in multiflower honey. Food Chemistry, $420 \quad 170,308-315$.

421 Codex Alimentarius, Codex Standard for Honey (CODEX STAN 12-1981), revision 2 (2011). 422 FAO/WHO. 
423 Consonni, R. \& Cagliani, L. R. (2008). Geographical characterization of polyfloral and acacia honeys 424 by nuclear magnetic resonance and chemometrics. Journal of Agricultural and Food Chemistry, 56, $425 \quad 6873-6880$.

426 Consonni, R., Cagliani, L. R., \& Cogliati, C. (2012). NMR characterization of saccharides in Italian 427 honeys of different floral sources. Journal of Agricultural and Food Chemistry, 60, 4526-4534.

428 Consonni, R., Cagliani, L. R., \& Cogliati, C. (2013). Geographical discrimination of honeys by 429 saccharides analysis. Food Control, 32, 543-548.

430 Conte, L. S., Miorini, M., Giomo, A., Bertacco, G., \& Zironi, R. (1998). Evaluation of some fixed 431 components for unifloral honey characterization. Journal of Agricultural and Food Chemistry, 46, $432 \quad 1844-1849$

Cotte, J. F., Casabianca, H., Chardon, S., Lhetier J. \& Grenier-Loustalot, M. F. (2003). Application of 434 carbohydrate analysis to verify honey authenticity. Journal of Chromatography, 1021, 145-155.

Donarski, J. A., Jones, S. A., \& Charlton, A. J. (2008). Application of cryoprobe ${ }^{1} \mathrm{H}$ nuclear magnetic 436 resonance spectroscopy and multivariate analysis for the verification of Corsican honey. Journal of Agricultural and Food Chemistry, 56, 5451-5456.

Donarski, J. A., Jones, S. A., Harrison, M., Driffield, M., \& Charlton, A. J. (2010). Identification of 439 botanical biomarkers found in Corsican honey. Food Chemistry, 118, 987-994.

440 Eriksson, L., Byrne, T., Johansson, E., Trygg, J., \& Wikström, C. (2013). Multi- and Megavariate Data 441 Analysis - Basic Principles and Applications. (3rd ed.). Malmö, Sweden: MKS Umetrics AB.

442 European Union (2002). Council Directive 2001/110/EC of 20 December 2001 relating to honey. 443 Official Journal of the European Communities, L10, 47-52. 
444 Fischer, M. K. \& Shingleton, A. W. (2001). Host plant and ants influence the honeydew sugar 445 composition of aphids. Functional Ecology, 15, 544-550.

446 Frérot, E., Velluz, A., Decorzant, E., \& Naef, R. (2006). From linden flower to linden honey. Part 2: 447 Glycosidic precursors of cyclohexa-1,3-diene-1-carboxylic acids. Chemistry \& Biodiversity, 3, 94448100.

449 Hermosín, I., Chicón, R. M., \& Dolores Cabezudo, M. (2003). Free amino acid composition and 450 botanical origin of honey. Food Chemistry, 83, 263-268.

451 Huttunen, S., Riihinen, K., Kauhanen, J., \& Tikkanen-Kaukanen, C. (2013). Antimicrobial activity of 452 different Finnish monofloral honeys against human pathogenic bacteria. APMIS, 121, 827-834.

453 Häusler, M. \& Montag, A. (1989). Isolation, identification and quantitative determination of the 454 norisoprenoid (S)-(+)-dehydrovomifoliol in honey. Zeitschrift für Lebensmittel-Untersuchung und 455 Forschung, 189, 113-115.

456 International Honey Commission (2009). Harmonised methods of the International Honey 457 Commission. www.ihc-platform.net/ihcmethods2009.pdf (accessed Sep 15, 2015).

458 Lolli, M., Bertelli, D., Plessi, M., Sabatini, A. G., \& Restani, C. (2008). Classification of Italian honeys 459 by 2D HR-NMR. Journal of Agricultural and Food Chemistry, 56, 1298-1304.

460 Louveaux, J., Maurizio, A., \& Vorwohl, G. (1978). Methods of melissopalynology. Bee World, 51, $461 \quad 125-131$. 

4641163.

465 Naef, R., Jaquier, A., Velluz, A., \& Bachofen, B. (2004). From the linden flower to linden honey 466 volatile constituents of linden nectar, the extract of bee-stomach and ripe honey. Chemistry \& 467 Biodiversity, 1, 1870-1879.

468 Ohmenhaeuser, M., Monakhova, Y. B., Kuballa, T., \& Lachenmeier, D. W. (2013). Qualitative and 469 quantitative control of honeys using NMR spectroscopy and chemometrics. ISRN Analytical 470 Chemistry, 2013, 1-9.

471 Persano Oddo, L. \& Bogdanov, S. (2004). Determination of honey botanical origin: problems and 472 issues. Apidologie, 35, S2-S3.

473 Persano Oddo, L., Piazza, M. G., Sabatini, A. G., \& Accorti, M. (1995). Characterization of unifloral 474 honeys. Apidologie, 26, 453-465.

475 Piana, M. L., Persano Oddo, L., Bentabol A., Bruneau, E., Bogdanov, S., \& Gyuot Declerck, C. (2004). 476 Sensory analysis applied to honey: state of the art. Apidologie, 25, S26-S37.

477 Rebane, R. \& Herodes, K. (2008). Evaluation of the botanical origin of Estonian uni- and polyfloral 478 honeys by amino acid content. Journal of Agricultural and Food Chemistry, 56, 10716-10720.

479 Ruoff, K., Luginbühl, W., Bogdanov, S., Bosset, J. O., Estermann, B., Ziolko, T., \& Amadò, R. (2006). 480 Authentication of the botanical origin of honey by near-infrared spectroscopy. Journal of 481 Agricultural and Food Chemistry, 54, 6867-6872. 
Salonen, A. (2011). Boreal unifloral honeys: Screening of composition and properties. Academic dissertation, University of Eastern Finland.

484

Salonen, A., Ollikka, T., Grönlund, E., Ruottinen, L., \& Julkunen-Tiitto, R. (2009). Pollen analyses of 485 honey from Finland. Grana, 48, 281-289. 487 components in complex mixtures: application to the metabonomics of amino acids in honey. 488 Analytical Chemistry, 77, 2455-2463.

489 Schievano, E., Peggion, E. \& Mammi, S. (2010). ${ }^{1} \mathrm{H}$ nuclear magnetic resonance spectra of 490 chloroform extracts of honey for chemometric determination of its botanical origin. Journal of 491 Agricultural and Food Chemistry, 58, 57-65.

492 Schievano, E., Stocchero, M., Morelato, E., Facchin, C. \& Mammi, S. (2012). An NMR-based 493 metabolomic approach to identify the botanical origin of honey. Metabolomics, 8, 679-690.

494 Schievano, E., Morelato, E., Facchin, C. \& Mammi, S. (2013). Characterization of markers of 495 botanical origin and other compounds extracted from unifloral honeys. Journal of Agricultural and 496 Food Chemistry, 61, 1747-1755.

497 Spiteri, M., Jamin, E., Thomas, F., Rebours, A., Lees, M., Rogers, K. M. \& Rutledge, D. N. (2015). 498 Fast and global authenticity screening of honey using ${ }^{1} \mathrm{H}-\mathrm{NMR}$ profiling. Food Chemistry, $189,60-$ 49966.

500 Steeg, E. \& Montag, A. (1987). Nachweis aromatischer Carbonsäuren in Honig. Zeitschrift für 501 Lebensmittel-Untersuchung und Forschung, 184, 17-19. 
502 Tomás-Barberán, F. A., Ferreres, F., García-Vignera, C., Tomás-Lorente, F. (1993). Flavonoids in 503 honey of different geographical origin. Zeitschrift für Lebensmittel-Untersuchung und Forschung, $504196,38-44$.

505 von der Ohe, W., Persano Oddo, L., Piana, M. L., Morlot, M., \& Martin, P. (2004). Harmonized 506 methods of melissopalynology. Apidologie, 35, S18-S25.

507 Zhou, J., Yao, L., Li, Y., Chen, L., Wu, L., \& Zhao, J. (2014). Floral classification of honey using liquid 508 chromatography-diode array detection-tandem mass spectrometry and chemometric analysis. 509 Food Chemistry, 145, 941-949.

510 Zieliński, Ł., Deja, S., Jasicka-Misiak, I., \& Kafarski, P. (2014). Chemometrics as a tool of origin 511 determination of polish monofloral and multifloral honeys. Journal of Agricultural and Food 512 Chemistry, 62 , 2973-2981. 
514 Figure $1 .{ }^{1} \mathrm{H}$ NMR spectra of the aqueous honey samples. (A) Superimposed spectra $(\delta$ 10.0-0.6 $515 \mathrm{ppm}$ ). (B) Overlaid spectral fingerprint regions ( $\delta$ 10.0-5.6 ppm and 2.9-0.6 ppm). From bottom to 516 top: buckwheat (samples 1, 2, 20; blue), dandelion (3-5, 18; yellow), honeydew (6, 7, 13; brown), 517 heather (10-12, 19; purple), clover (8; dark green), linden (9; green), Himalayan balsam (14; pink), 518 multifloral (15, 17; gray), and lingonberry (16; red) honeys.

519 Figure 2. Highlighted fingerprints for buckwheat (blue), dandelion (yellow), heather (purple), 520 honeydew (brown), linden (green), and lingonberry (red) honeys. Spectral regions (A) 1.50-0.75 521 ppm, (B) 2.94-1.50 ppm, (C) 4.70-4.10 ppm, (D) 5.50-4.93 ppm, and (E) 9.50-5.60 ppm. 522 Abbreviations: Ala, alanine; HMF, 5-hydroxymethylfurfural; Ile, isoleucine; Leu, leucine; Phe, 523 phenylalanine; Pro, proline; Tyr, tyrosine; Val, valine. Peak multiplicities: s, singlet; d, doublet; dd 524 doublet of doublets; $m$, multiplet; $t$, triplet.

525 Figure 3. ${ }^{1} \mathrm{H}$ NMR assignments $\left(600 \mathrm{MHz}, \mathrm{H}_{2} \mathrm{O}+10 \% \mathrm{D}_{2} \mathrm{O}, \mathrm{pH} 6.55,298 \mathrm{~K}\right)$ for the dandelion honey 526 markers. (A) 2-Hydroxy-3-methylbutyric acid, (B) 2-hydroxy-3-methylpentanoic acid, (C) 3-methyl527 2-oxopentanoic acid, and (D) 4-methyl-2-oxopentanoic acid. (Structures: Chenomx NMR Suite 8.0 528 Profiler).

529 Figure 4. PCA model (t[2] vs. $t[1])$. The $R^{2} X_{(\text {cum })}$ and $Q_{(\text {cum) }}^{2}$ for the model were 0.99 and 0.96 , 530 respectively. (A) Scores plot $\left(R^{2} X[1]=0.50\right.$ and $\left.R^{2} X[2]=0.33\right)$. The legend indicates the honey type. 531 (B) Loadings plot. Figure 5. OPLS-DA comparison of buckwheat, dandelion and heather honeys. (A) Score overview of 533 the of the three classes ( $t[2]$ vs. $\left.t[1]) ; R^{2} X_{\text {(cum) }}=0.94, R^{2} Y_{\text {(cum) }}=0.98, Q_{(\text {cum) }}^{2}=0.96\right)$. (B) Buckwheat 534 and dandelion honey (to[1] vs. $\left.t[1] ; R^{2} X_{\text {(cum) }}=0.91, R^{2} Y_{(\text {cum })}=1.00, Q_{(\text {cum })}^{2}=0.98\right)$. (C) Dandelion 
535 and heather honey (to[1] vs. $\left.t[1] ; R^{2} X_{\text {(cum) }}=0.93, R^{2} Y_{\text {(cum) }}=0.98, Q_{(\text {cum) }}^{2}=0.97\right)$. (D) Buckwheat and 536 heather honey (to[1] vs. $t[1] ; R^{2} X_{\text {(cum) }}=0.95, R^{2} Y_{\text {(cum) }}=1.00, Q_{\text {(cum) }}^{2}=0.99$ ). (E) Loadings 537 distribution between buckwheat and dandelion. (F) Loadings distribution between dandelion and 538 heather. (G) Loadings distribution between buckwheat and heather.

539 Figure 6. Validation tests of the OPLS-DA models in Fig. 5A-D, respectively, by permutation $(n=$ $54020)$ of corresponding PLS-DA models $\left(R^{2}\right.$, green triangle; $Q^{2}$, blue square). Intercepts: (A) $R^{2}=(0.0$, $5410.26), Q^{2}=(0.0,-0.66),(\mathrm{B}) R^{2}=(0.0,0.26), Q^{2}=(0.0,-0.66),(\mathrm{C}) R^{2}=(0.0,0.38), Q^{2}=(0.0,-0.47)$, 542 and (D) $R^{2}=(0.0,0.48), Q^{2}=(0.0,-0.48)$. 
Figure 1

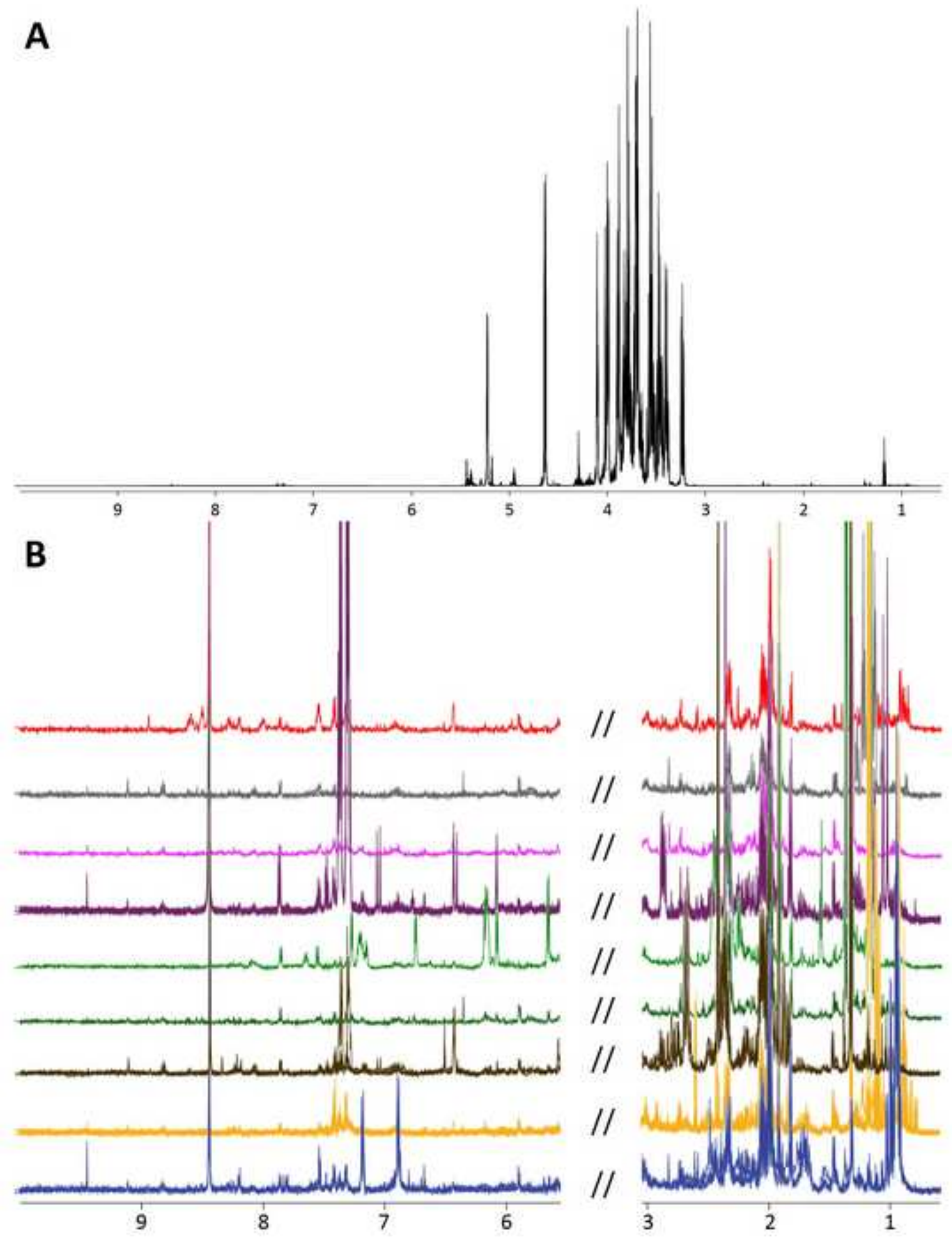




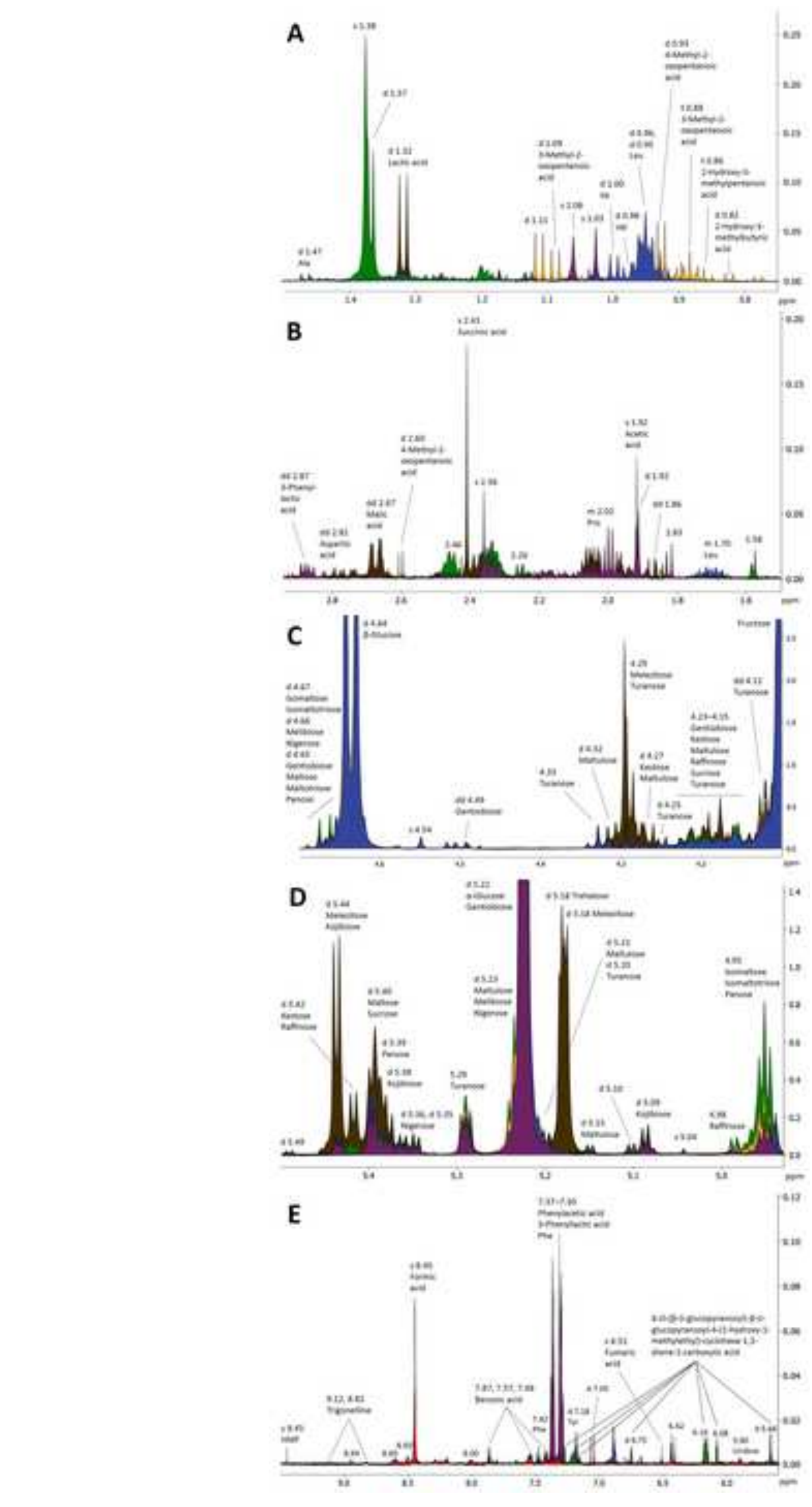

Figure 2

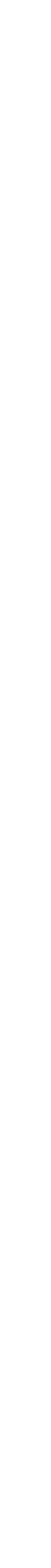

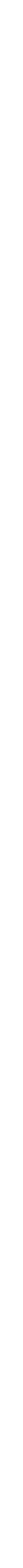

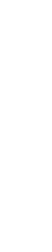



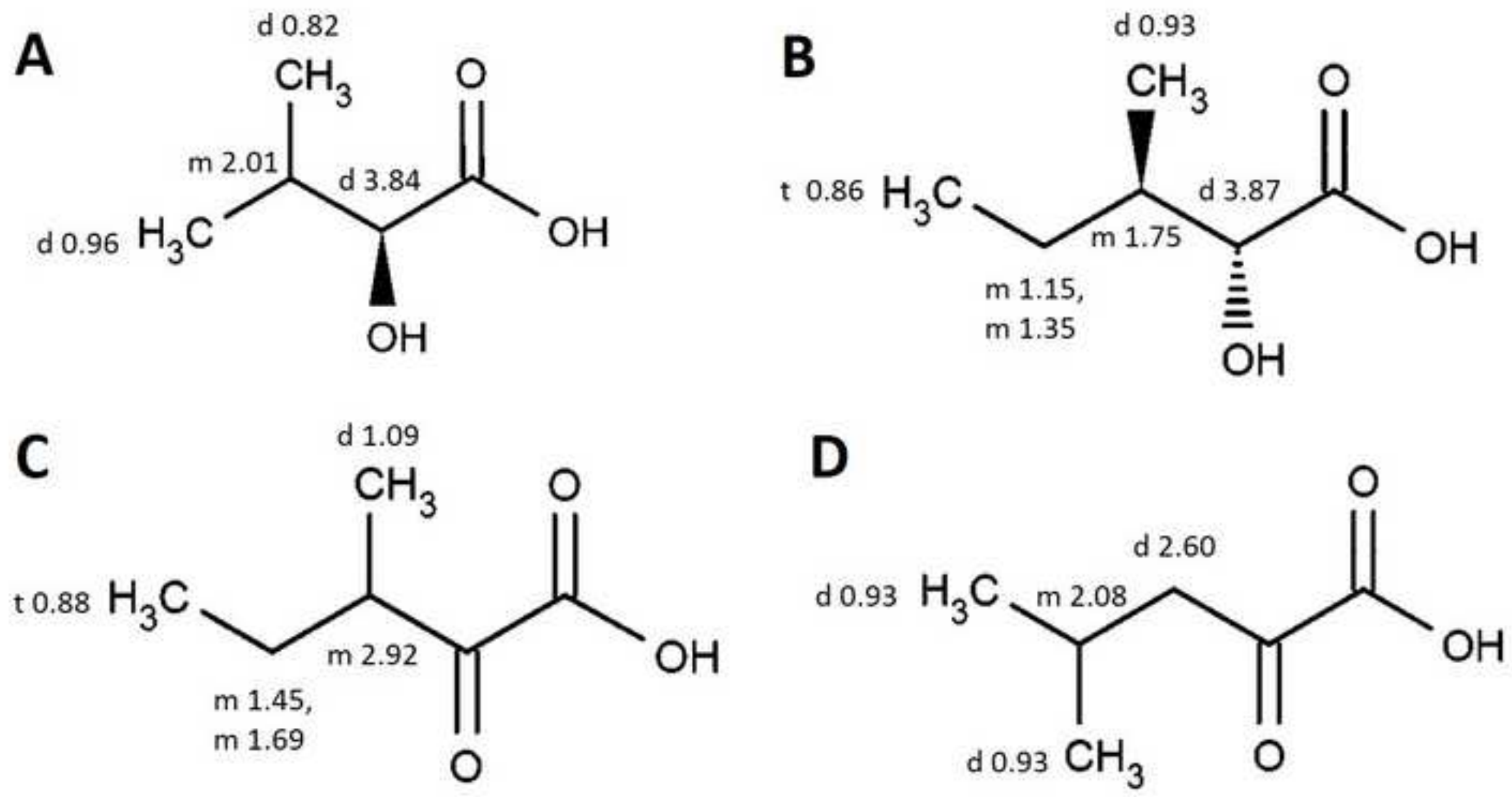


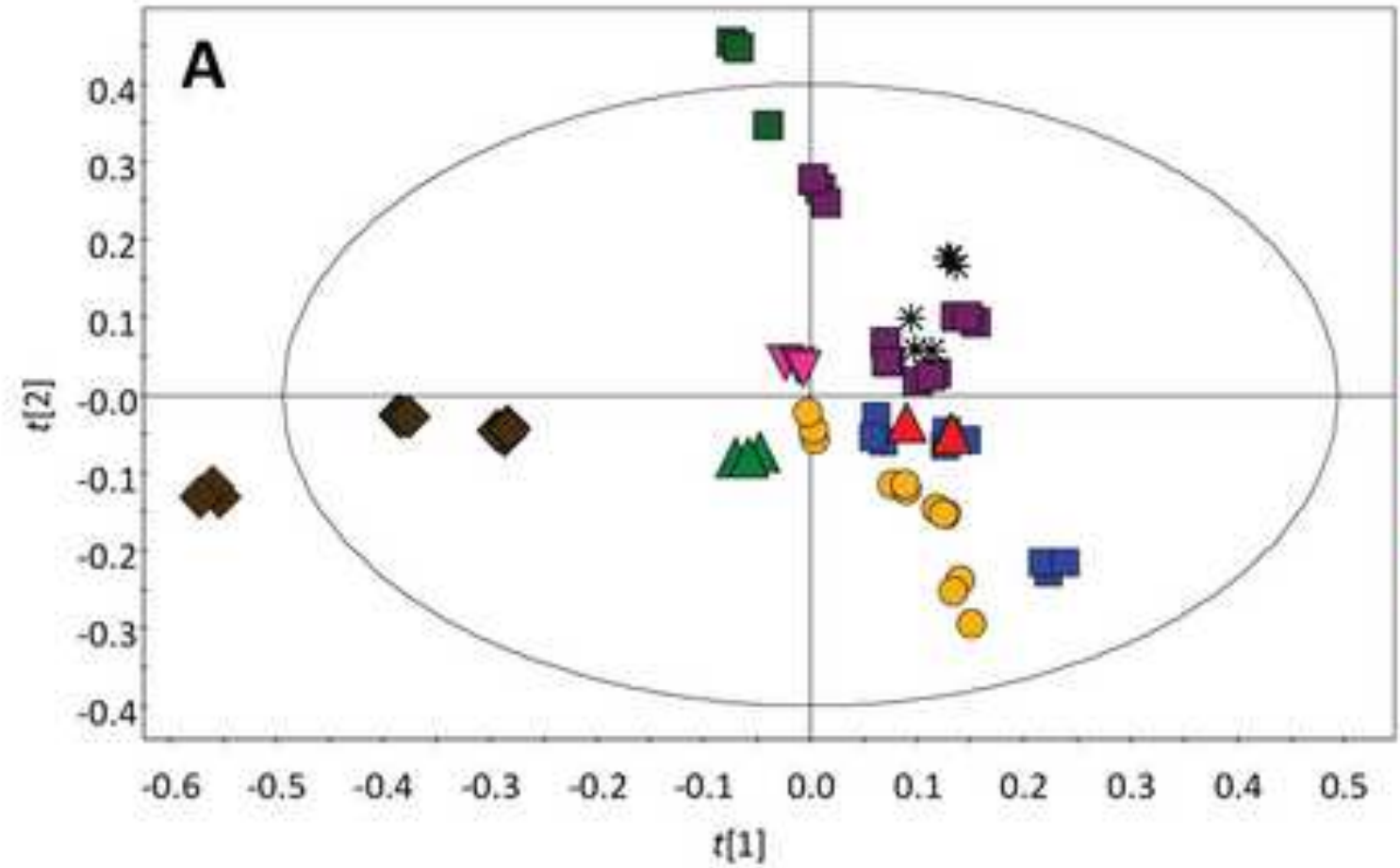

四 Buckwheat

O Dandelion

Honeydew

Clover

$\Delta$ Linden

Heather

$\checkmark$ Himalayan balsam

* Multifloral

$\Delta$ Lingonberry

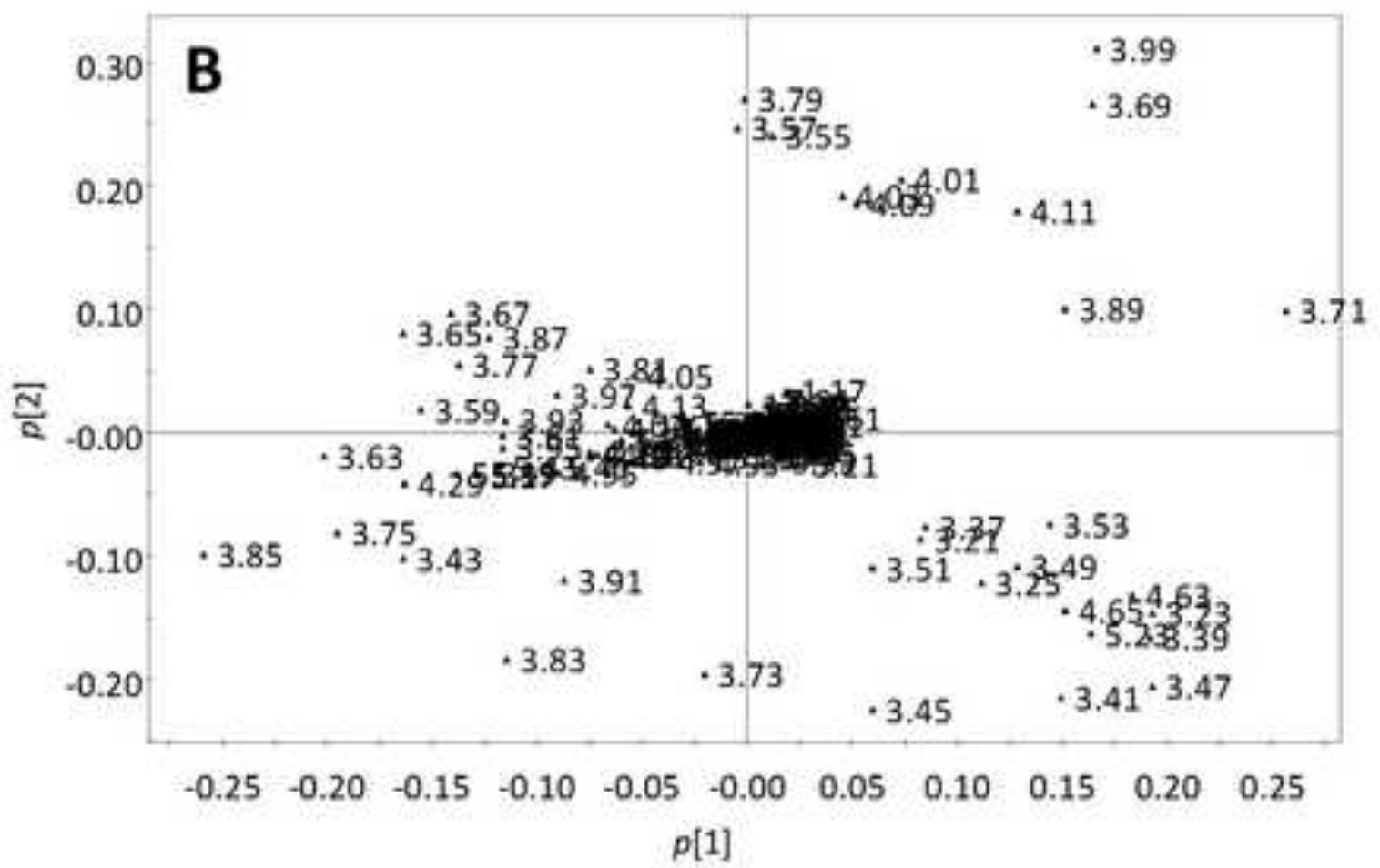


Figure 5
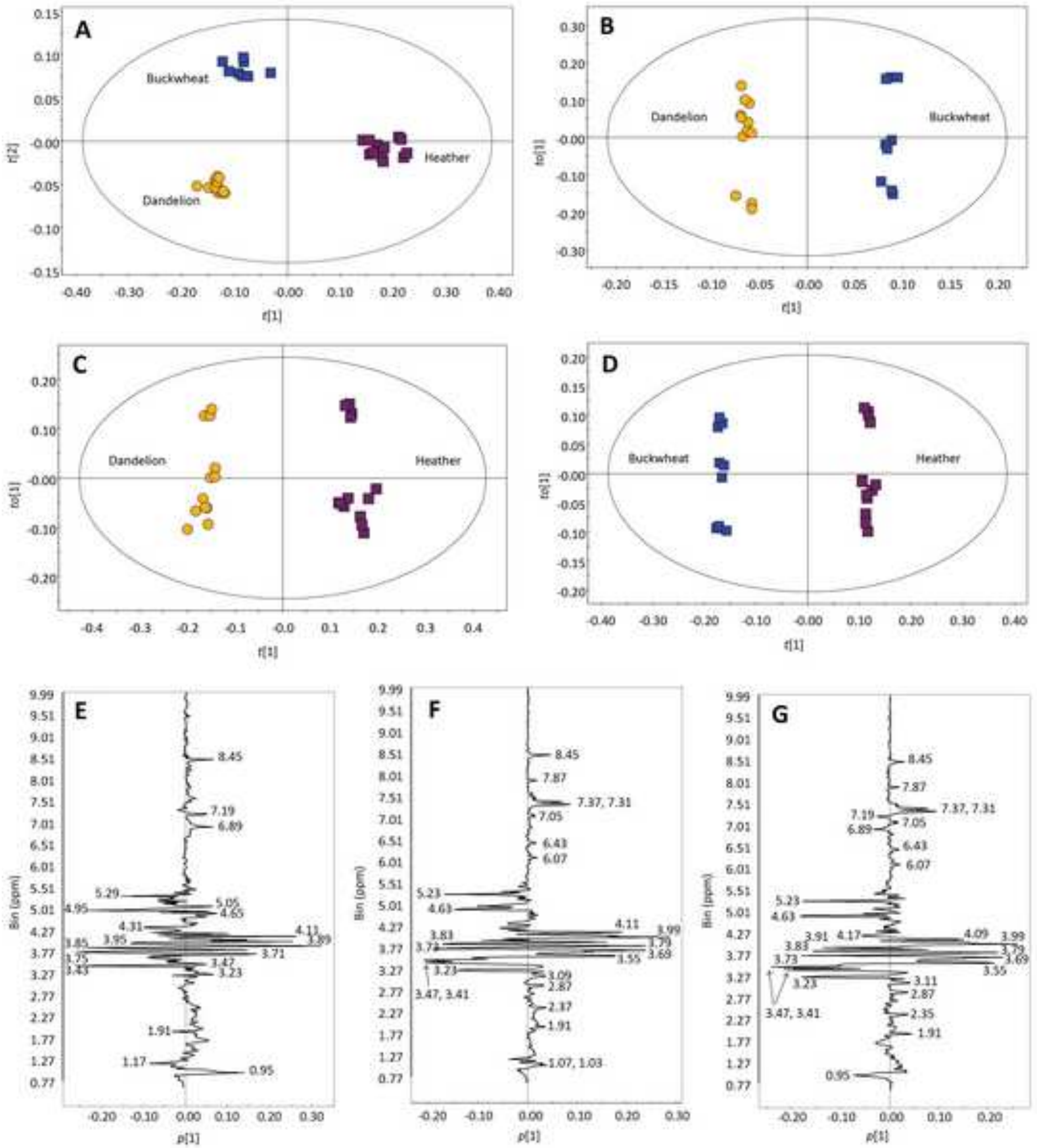

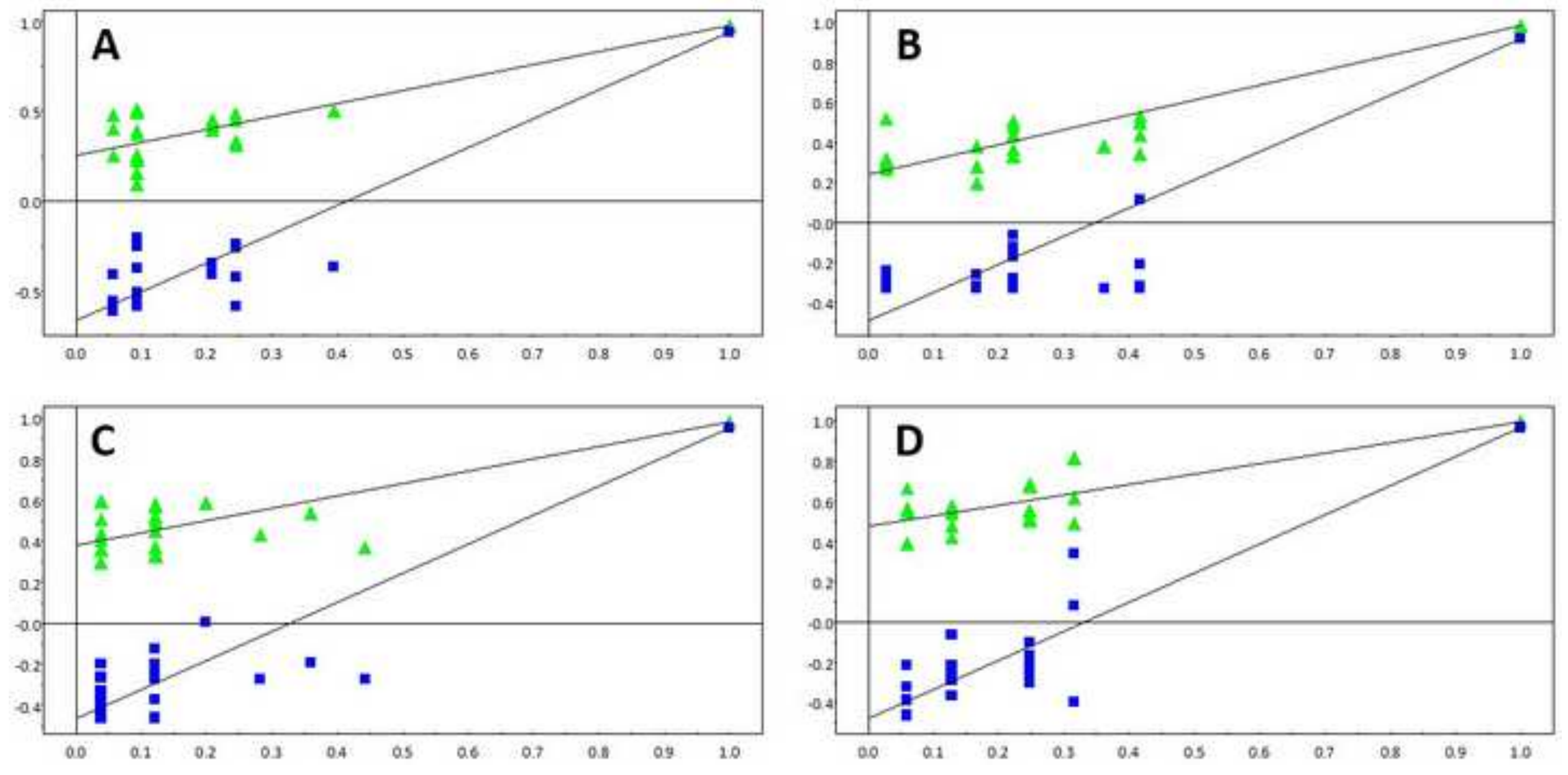
Table 1. Honey samples. The exact geographical origin of the samples $18-20$ is not known.

\begin{tabular}{|c|c|c|c|c|}
\hline Sample no. & Botanical origin & & Geographical origin & Harvest year \\
\hline 1 & Buckwheat & Fagopyrum esculentum & $60^{\circ} \mathrm{N} 23^{\circ} \mathrm{E}$, Loimaa (southwestern Finland) & 2012 \\
\hline 3 & Dandelion & Taraxacum spp. & $60^{\circ} \mathrm{N} 21^{\circ} \mathrm{E}$, Parainen (southwestern Finland) & 2012 \\
\hline 5 & Dandelion & Taraxacum spp. & $62^{\circ} \mathrm{N} 30^{\circ} \mathrm{E}$, llomantsi (eastern Finland) & 2013 \\
\hline 6 & Honeydew & & $62^{\circ} \mathrm{N} 29^{\circ} \mathrm{E}$, Joensuu (eastern Finland) & 2013 \\
\hline 7 & Honeydew & & $62^{\circ} \mathrm{N} 25^{\circ} \mathrm{E}$, Jyväskylä (central Finland) & 2013 \\
\hline 8 & Clover & Trifolium repens/hybridum & $62^{\circ} \mathrm{N} 29^{\circ} \mathrm{E}$, Joensuu (eastern Finland) & 2012 \\
\hline 11 & Heather & Calluna vulgaris & $61^{\circ} \mathrm{N} 21^{\circ} \mathrm{E}$, Rauma (southwestern Finland) & 2012 \\
\hline 12 & Heather & Calluna vulgaris & $63^{\circ} \mathrm{N} 23^{\circ} \mathrm{E}$, Kaustinen (central Finland) & 2013 \\
\hline 13 & Honeydew & & $64^{\circ} \mathrm{N} 26^{\circ} \mathrm{E}$, Vaala (central Finland) & 2013 \\
\hline 14 & Himalayan balsam & Impatiens glandulifera & $64^{\circ} \mathrm{N} 24^{\circ} \mathrm{E}$, Ylivieska (central Finland) & 2013 \\
\hline 15 & Multifloral & & $60^{\circ} \mathrm{N} 24^{\circ} \mathrm{E}$, Hämeenlinna (southern Finland) & 2013 \\
\hline 16 & Lingonberry & Vaccinium spp. & $63^{\circ} \mathrm{N} 28^{\circ} \mathrm{E}$, Rautavaara (eastern Finland) & 2013 \\
\hline
\end{tabular}




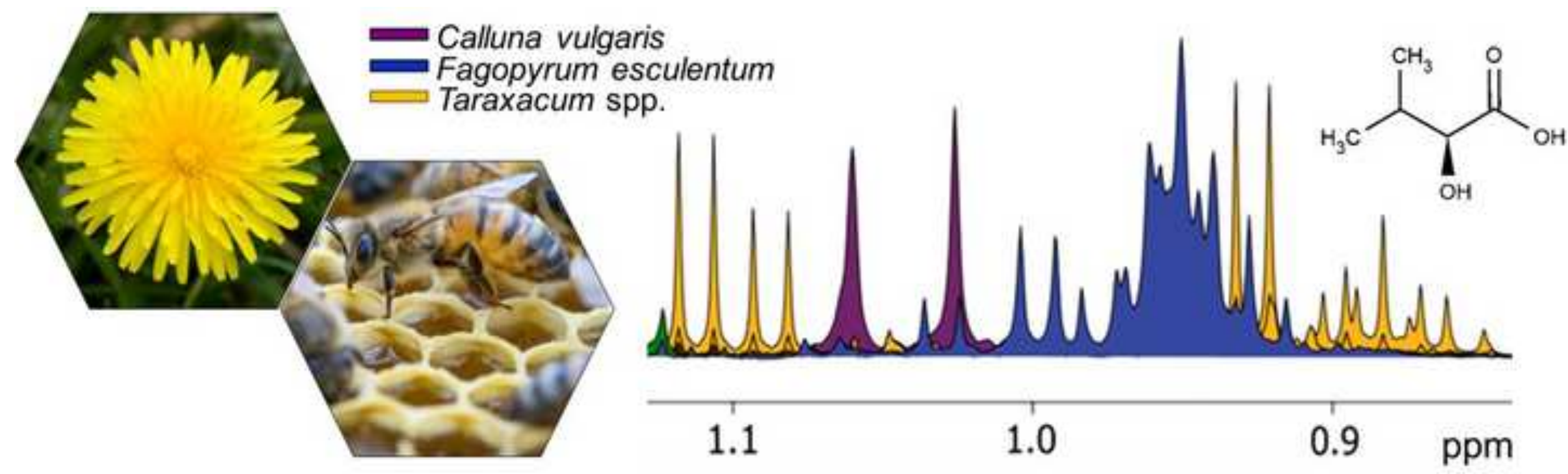

